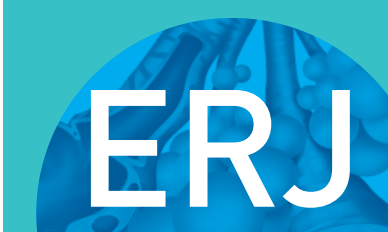

open research
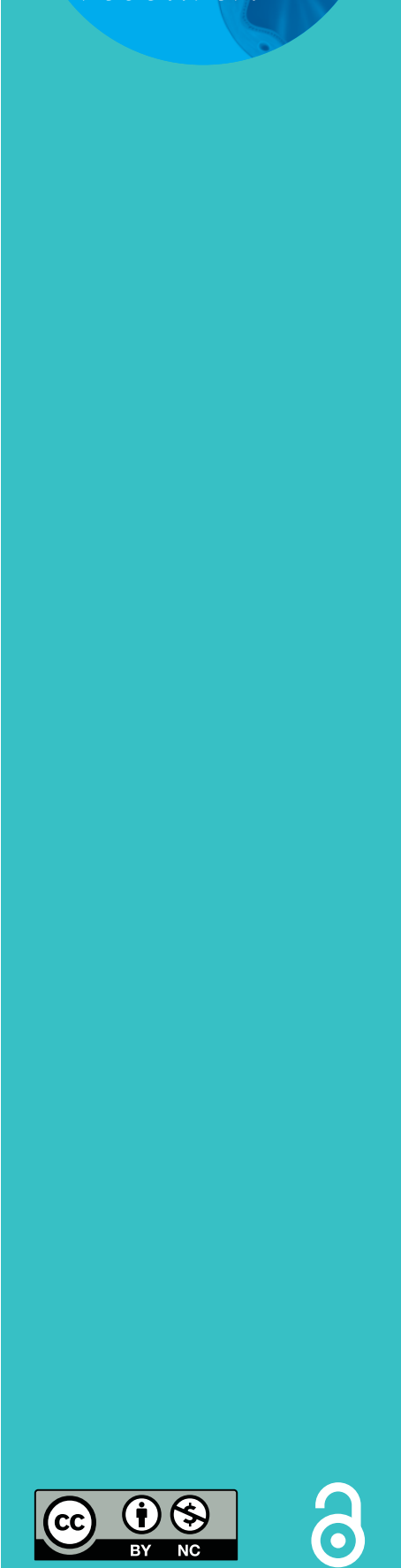

\section{European Respiratory Society International Congress 2017: highlights from the Clinical Assembly}

\author{
Nicolas Kahn ${ }^{1,2}$, Evgeni Mekov ${ }^{3}$, Laura Fregonese ${ }^{4}$, Vasileios Andrianopoulos $\mathbb{C}^{5}$, \\ Frits M.E. Franssen ${ }^{6}{ }^{6}$, Aleksandar Grgic ${ }^{7}$, Johan Coolen ${ }^{8}$, Peter I. Bonta ${ }^{9}$, \\ Daniela Gompelmann ${ }^{1,2}$, Jouke T. Annema ${ }^{9}$, Paola Faverio ${ }^{10}$, \\ Francesco Bonella ${ }^{11}$, Luke Daines ${ }^{12}$, Hillary Pinnock ${ }^{12}$, Janwillem Kocks ${ }^{13,14}$ and \\ Felix Herth ${ }^{1,2}$
}

\begin{abstract}
Affiliations: ${ }^{1}$ Pneumology and Critical Care Medicine, Thoraxklinik at Heidelberg University Hospital, Heidelberg, Germany. ${ }^{2}$ Translational Lung Research Center, Member of the German Center for Lung Research, Heidelberg, Germany. ${ }^{3}$ Medical University - Sofia, Medical Faculty, Clinical Center for Pulmonary Diseases, MHATPD "Sveta Sofia", Sofia, Bulgaria. "Product Development Scientific Support Department, European Medicines Agency, London, UK. ${ }^{5}$ Dept of Respiratory Medicine and Pulmonary Rehabilitation, Schoen Klinik Berchtesgadener Land, Schoenau am Koenigssee, Germany. ${ }^{6}$ Dept of Research and Education, CIRO, Horn, The Netherlands. ${ }^{7}$ Dept of Nuclear Medicine, Saarland University Medical Center, Homburg, Germany. ${ }^{8}$ Radiology Dept, KU Leuven - University of Leuven, University Hospitals Leuven, Leuven, Belgium. ${ }^{9}$ Dept of Respiratory Medicine, AMC, Amsterdam, The Netherlands. ${ }^{10}$ Dept of Health Science, University of Milan Bicocca, Clinica Pneumologica, AO San Gerardo, Monza, Italy. ${ }^{11}$ Interstitial and Rare Lung Disease Unit, Ruhrlandklinik, University Hospital, University of Duisburg-Essen, Essen, Germany. ${ }^{12}$ Usher Institute of Population Health Sciences and Informatics, University of Edinburgh, Edinburgh, UK. ${ }^{13}$ University of Groningen, University Medical Center Groningen, Dept of General Practice and Elderly Care Medicine, Groningen, The Netherlands. ${ }^{14}$ University of Groningen, University Medical Center Groningen, GRIAC Research Institute, Groningen, The Netherlands.
\end{abstract}

Correspondence: Felix Herth, Pneumology and Critical Care Medicine, Thoraxklinik at University of Heidelberg, Röntgenstrasse 1, 69126 Heidelberg, Germany. E-mail: felix.herthamed.uni-heidelberg.de

ABSTRACT This article contains highlights and a selection of the scientific advances from the European Respiratory Society's Clinical Assembly (Assembly 1 and its six respective groups) that were presented at the 2017 European Respiratory Society International Congress in Milan, Italy. The most relevant topics from each of the groups will be discussed, covering a wide range of areas including clinical problems, rehabilitation and chronic care, thoracic imaging, interventional pulmonology, diffuse and parenchymal lung diseases, and general practice and primary care. In this comprehensive review, the newest research and actual data as well as award-winning abstracts and highlight sessions will be discussed.

@ERSpublications

A highlights review of selected presentations from \#ERSCongress 2017 by the @ERStalk Clinical Assembly http://ow.ly/p3fB30gSb24

Cite this article as: Kahn N, Mekov E, Fregonese L, et al. European Respiratory Society International Congress 2017: highlights from the Clinical Assembly. ERJ Open Res 2018; 4: 00134-2017 [https:// doi.org/10.1183/23120541.00134-2017].

Received: Oct 302017 | Accepted after revision: Nov 242017

Conflict of interest: Disclosures can be found alongside this article at openres.ersjournals.com

Copyright $\odot$ ERS 2018. This article is open access and distributed under the terms of the Creative Commons Attribution Non-Commercial Licence 4.0. 


\section{Introduction}

The Clinical Assembly of the European Respiratory Society (ERS) is the largest of the now 13 assemblies. A vast number of abstracts are presented through this assembly and the six groups of which it consists. It is impossible for any delegate to follow all scientific and clinical advances and breakthroughs presented during this conference. This review aims to provide the esteemed reader with an overview of a few of the most interesting presentations of each group, deemed noteworthy by the authors of this manuscript.

\section{Group 1.1: Clinical Problems}

Chronic obstructive pulmonary disease management, physical activity and biomarkers

The current management of chronic obstructive pulmonary disease (COPD) was discussed in oral presentations and posters sessions with particular focus on the changes of the 2017 Global Initiative for Chronic Obstructive Lung Disease (GOLD) classification compared to GOLD 2011. Special attention was also paid to quality of life, physical activity and biomarkers.

Self-administered COPD Assessment Test (CAT) questionnaires had significantly higher scores than those reported with physician assistance (8.0 versus 12.6 , considerably higher than the minimal clinically important difference of 2 points) [1]. Although the CAT questionnaire is validated for self-assessment, and physician assistance may underestimate symptoms and the impact of the disease, on the other hand, it may clarify misunderstanding of the questions. Paper versions of CAT and Evaluating Respiratory Symptoms in COPD questionnaires are associated with higher scores than their electronic version (10.0 versus 8.6 and 6.8 versus 5.0, $\mathrm{p}<0.001$ ) [2]. LINDQVIST et al. [3] showed that the CAT score increases rapidly with progression of lung parenchymal damage measured by ventilation and perfusion tomography while obstructive bronchitis plays a minor role.

Physical activity remains an important field of research in COPD. As suggested by DemeYer et al. [4], every step counts, as both the quantity and intensity of physical activity correlate with mortality, and the strength of this observation is comparable across GOLD stages. Dual long-acting $\beta_{2}$-agonist plus long-acting muscarinic antagonist bronchodilator therapy was shown to significantly improve physical activity in the ACTIVATE study [5] as well as in a meta-analysis of eight randomised controlled trials (RCTs) [6]. Severe exacerbation symptoms were associated with reduced physical activity both in outpatients [7] and hospitalised patients, as seen in the REACH trial [8]. CHIARADIA et al. [9] addressed the impact of iron deficiency on daily physical activity, showing that it almost halved the number of steps per day (3628 versus 7072). Sedentary lifestyle causes changes in muscle thickness [10] and it was proposed that COPD patients with more physical activity may represent a separate phenotype [11].

A large number of abstracts addressed the topic of biomarkers. The analysis of 42142 COPD patients from a large database confirmed the association between high eosinophil counts $\left(\geqslant 0.45 \times 10^{9}\right.$ cells $\left.\cdot \mathrm{L}^{-1}\right)$ and increased risk of exacerbations irrespective of treatment regimen [12]. A small study reported, on the other hand, fewer and shorter hospitalisations in patients with $\geqslant 4 \%$ peripheral blood eosinophils during exacerbations and normal eosinophils at baseline [13]. Mepolizumab reduced the rate of moderate/severe exacerbations and increased time to first moderate/severe exacerbation in patients with eosinophilic COPD [14].

\section{Asthma control, biomarkers and asthma-COPD overlap syndrome}

Asthma was extensively covered at the ERS Congress, with several studies exploring biomarkers and some interesting findings from large cohort studies.

Small exploratory studies showed the association of asthma control with inflammatory biomarkers such as serum interleukin (IL)-6 [15] and IL-13 [16]. Significantly elevated IL-27 protein levels have been described by PABREJA et al. [17] in eosinophilic asthma but not in neutrophilic and paucigranulocytic asthma, suggesting a functional role of IL-27 in the eosinophilic endotype. Patients with asthma and high blood eosinophil counts $\left(\geqslant 0.35 \times 10^{9}\right.$ cells $\left.\cdot \mathrm{L}^{-1}\right)$ have increased risk of exacerbations despite stable treatment with medium- or high-dose inhaled corticosteroids and good adherence [18].

A large population-based prospective cohort study reported that incident asthma-COPD overlap is associated with lifestyle and socioeconomic status factors such as smoking, ever use of hormone therapy, unemployment and being divorced, whereas physical activity and high education were associated with lower risk [19]. Patients with asthma-COPD overlap syndrome (ACOS) have high prevalence (two to three times higher) of insomnia and respiratory symptoms than those with asthma or COPD alone [20]. In a population-based cohort of 1037 young adults, high blood eosinophil counts were associated with airflow obstruction independently of asthma and smoking [21]. Eosinophilia was linked to lung function decline and development of progressive airflow obstruction from age 21 to 38 years in young adults without a respiratory diagnosis or symptoms. In a study by De LA CRUZ CASTRO et al. [22], patients with asthma and/ 
or rhinitis suffered significantly more traffic accidents than the healthy population in the control group. The accident rate was related to the severity of asthma and rhinitis.

\section{Group 1.2: Pulmonary Rehabilitation and Chronic Care}

The abstracts presented in the field of pulmonary rehabilitation (PR) and chronic care provided a rich array of information regarding methodological issues in patients' and outcomes assessment, new therapeutic interventions and models of care delivery, and alternative target populations. The most highly rated abstracts of the group, which were presented in a competitive oral presentation session, are summarised below.

Exercise training is widely regarded as the cornerstone of PR programmes, and is highly beneficial in patients with chronic lung disease for improving clinical symptoms, exercise tolerance and health status; however, the benefits obtained may be influenced by the type of lung disease and exercise training. KUMAR et al. [23] performed a RCT in 60 patients with non-cystic fibrosis bronchiectasis (NCFB) and reported significant improvements in exercise and aerobic capacity, depression and anxiety levels, and quality of life in the PR group compared to the control group. The authors concluded that PR should be part of routine care for NCFB patients. Also investigating patients with bronchiectasis, ColE et al. [24] performed a propensity-matched study comparing the completion rates and outcomes of outpatient PR between patients with this condition and those with COPD. They demonstrated that PR in patients with bronchiectasis provided similar improvements in exercise capacity and health status compared to COPD patients. Moreover, completion rates were similar (74\%) in both patient groups.

In another patient category, in cystic fibrosis (CF), KALTSAKAS et al. [25] investigated the effectiveness of two different types of exercise training: high-intensity interval exercise (IE) and moderate-intensity constant-load exercise (CLE). The study included 24 ambulatory CF patients and showed that IE is equally effective as CLE. Since oxygen saturation was higher during IE and intensity of dyspnoea was lower than during CLE, IE may be the preferred exercise training modality for CF patients.

Arizono et al. [26] performed a randomised crossover study to investigate the effect of Suppl.emental oxygen versus room air on exercise capacity in 46 idiopathic pulmonary fibrosis (IPF) patients with exercise-induced hypoxaemia. Oxygen Supplementation increased endurance time and minimal oxygen saturation compared with room air, and this effect was independent of the mean pulmonary arterial pressure in these patients.

Since availability of hospital-based PR is limited in parts of the world, and general uptake and completion of those programmes are poor, Kaliaraju et al. [27] performed a matched case-control study comparing the efficacy of PR in 154 COPD patients undergoing an unsupervised home-based programme and 154 patients participating in outpatient supervised PR. Improvements in exercise capacity were more pronounced in the outpatient supervised PR group, while changes in health status were similar between groups. In general, compliance to the programmes was low. CoERTJENs et al. [28] also demonstrated improvements in exercise capacity after PR consisting of a combination of strength and endurance training in a group of 20 "critical" patients with COPD. They reported a good correlation between changes in stair climbing test and 6-min walk distance, and suggested that strength training may present greater repercussion in functional tests.

Finally, ANDRIANOPOULOS et al. [29] investigated whether cognitively impaired patients with COPD are characterised by impaired cerebral blood flow regulation. This might result in inadequate cerebral oxygen availability to meet the increased metabolic demands during exercise that could be associated with the manifestations of cognitive impairment. They demonstrated that cognitively impaired patients preserve the capacity to maintain cerebral oxygen availability unchanged during submaximal exercise compared to cognitively normal patients with COPD. The authors concluded that rehabilitative exercise training in cognitively impaired patients with COPD, who exhibit mild to moderate exercise-induced reduction in oxygen saturation measured by pulse oximetry, is deemed safe.

\section{Group 1.3: Chest Imaging}

At the 2017 ERS International Conference, interesting data on several imaging techniques for a wide variety of diseases were presented. One of the emphases of the presented abstracts was on COPD and emphysema. Mineshita et al. [30] measured the ratio of cardiac/lung area in expiratory plain chest radiographs and correlated this parameter with airflow limitations in patients with COPD. They found a strong correlation between these two parameters, particularly in patients with severe and very severe COPD (GOLD III and IV).

RoBbie et al. [31] analysed serial computed tomography (CT) examinations to measure the volume loss of lung parenchyma in patients with IPF. They evaluated serial CT parameters of lung volume loss and 
pulmonary function tests against mortality. Particularly, the change in anterior junction distance predicted mortality more strongly than the change in annual percentage forced vital capacity (FVC).

Spatiotemporal ventilation heterogeneity $(\mathrm{VH})$ is one of the essential features of asthma. BELL et al. [32] used imaging biomarkers of $\mathrm{VH}$ extracted from parametric response maps of registered inspiratory and expiratory CT scans in asthma patients. They concluded that their newly developed imaging biomarker based on stratified axial CT analysis could contribute to $\mathrm{VH}$ discrimination. CT measurements of lung density are potential intermediate study endpoints for clinical studies. However, the clinical associations of variations in lung density and changes in forced expiratory volume $1 \mathrm{~s}$ (FEV1) in smokers with and without COPD are not well understood. DiAz et al. [33] demonstrated that a decline in lung density was associated with an increase or decrease in FEV1, based on disease severity. This FEV1-CT lung density relationship should be taken into account when using CT imaging as an endpoint in longitudinal COPD studies. TSCHIRREN et al. [34] examined the shape of the central airways in order to evaluate phenotypes of COPD. They showed that central airway shapes change significantly across the vital capacity with distinctly different shape changes detectable across GOLD statuses.

A few more innovative abstracts focused on use of magnetic resonance imaging (MRI) in different diseases. EDDY et al. [35] used hyperpolarised noble gas MRI before and after bronchodilator inhalation to evaluate ventilation reversibility in asthma and COPD patients with potential ACOS. Regardless of FEV 1 reversibility, their data revealed that one third of patients showed a reversibility of post-dilator ventilation defects. Hughes et al. [36] used distribution of coefficient of variation (CoV) values in patients with CF, asthma and normal controls by histogram analysis of hyperpolarised ventilation MRI to examine ventilation heterogeneity. They reported different $\mathrm{CoV}$ metrics in all three cohorts; however, $\mathrm{CoV}$ distributions appear to change with disease severity and may be used to assess disease progression. Furthermore, using hyperpolarised gases, diffusion weighted imaging can also be obtained. CHAN et al. [37] evaluated estimates of lung morphometry from two models of gas diffusion in healthy controls, and IPF and COPD patients. Both models (stretched exponential model and cylinder model) showed a strong nonlinear relationship. The authors assume that this results from inherent differences in model assumptions.

Similarly, WeATHERLEY et al. [38] investigated microstructural metrics and regional gas exchange in patients with IPF, which can both provide information on early functional deterioration before it is detectable by diffusing capacity measurement.

Finally, nuclear medicine methods were also presented. SINGH et al. [39] examined patients with sarcoidosis by using ${ }^{68} \mathrm{Ga}$-DOTA-NOC positron emission tomography (PET)/CT as a predictor of disease activity. They found that DOTA-NOC PET/CT emerged as a useful tool to detect clinical activity and treatment response in sarcoidosis patients.

\section{Group 1.4: Interventional Pulmonology}

Due to technological advancements and innovations, several new interventional procedures have been developed for a wide range of diagnostic and therapeutic purposes for patients with lung cancer, interstitial lung disease (ILD) and severe obstructive lung diseases. Some of these interventions have been incorporated into recent guidelines whereas the position of others is still under investigation. The broad interest of ERS Congress attendees in interventional pulmonology was reflected by the large attendance at the second ever ERS Live Endoscopy session this year in Milan-Ancona.

\section{Lung cancer/malignant pleural effusion}

Lung cancer staging guidelines state that endosonography is the initial test of choice for mediastinal nodal tissue staging [40]. Several abstracts were related to optimise nodal staging approaches including the use of endobronchial ultrasound (EBUS) followed by the introduction of the EBUS scope into the oesophagus (EUS-B) for additional nodal sampling. In the multicentre SCORE study, 229 patients with resectable (suspected) non-small cell lung cancer (NSCLC) were prospectively evaluated. A systematic EBUS investigation of all mediastinal nodes followed by an oesophageal nodal evaluation (EUS-B) versus an EBUS targeted nodal "hit and run" approach increased the sensitivity and negative predictive value of N2-N3 disease from $79 \%$ to $87 \%$ and $85 \%$ to $91 \%$, respectively [41]. The STAGE study reported on the role of combined EBUS and EUS-B staging in 94 patients with NSCLC in whom curative stereotactic ablative radiotherapy was considered [42]. After complete hilar and mediastinal endosonographic staging, $11 \%$ of the patients were up-staged from N0 to N1; whereas in the N1 and N2-3 groups $85 \%$ and $65 \%$ of the patients, respectively, were down-staged to cN0.

To date, the diagnostic characteristics of needle biopsies for lung cancer diagnostics are limited by a substantial false-negative rate. The concept of so-called smart needles that are able to detect metastasis in 
"real time" by acting as a "live microscope" might overcome this drawback. Needle-based confocal laser endomicroscopy is a promising technique for this purpose. With a sensitivity of $90 \%$ and diagnostic accuracy of $89 \%$, metastatic mediastinal lymph nodes were differentiated from reactive nodes using an endosonographic approach [43].

Malignant pleural effusions (MPEs) are common and many open questions remain on their optimal management. The IPC-Plus trial randomised 154 malignant pleural effusion patients over 4 years to examine whether administering talc via an indwelling pleural catheter (IPC) leads to a greater chance of pleurodesis when compared to using an IPC alone. Talc was administered after 10 days once significant trapped lung had been excluded, with participants managed as outpatients. The data showed that those receiving the intervention were around twice as likely to have achieved pleurodesis by 5 weeks than those who did not, without any suggestion of harm to the patient from the IPC itself [44]. The investigators of the PROMISE Study managed to develop and prospectively validate a prognostic score for MPE patients to estimate risk of 3-month mortality. They studied differential protein expression from five separate and independent patient cohorts in order to establish a prognostic and therapeutic score for MPE [45].

\section{Interstitial lung disease}

Specific ILD diagnosis, made by a multidisciplinary team (MDT) taking clinical, imaging and pathology features into account, is key to determining prognosis and treatment. Several abstracts presented data on transbronchial lung cryobiopsy (TBLC), a relatively novel bronchoscopic technique by which large alveolar tissue samples can be obtained. In 90 patients with suspected ILD and the need for a tissue diagnosis, the diagnostic yield of TBLC in obtaining a histological diagnosis was 73.3\% [46]. For those patients ( $\mathrm{n}=11)$ in which TBLCs were taken from two different lobes, histological diagnostic yield was $91 \%$ indicating an additive diagnostic impact of this strategy. Pneumothorax occurred in $22.4 \%$ of patients and no severe bleeds were reported. Novel bronchoscopic imaging techniques that are able to visualise the alveolar compartment might contribute to ILD diagnosis, improve of the diagnostic yield of TBLC or even prevented the need to take biopsy samples. Optical coherence tomography (OCT) is a laser-based, high-resolution imaging technique. In 11 ILD patients, OCT imaging-based alveolar compartment characteristics were identified and compared to histological biopsies taken by the cryo technique. OCT imaging in these patients was able to visualise thickening/loss of alveolar septa, microscopic honeycombing and bronchiectasis to a more detailed level than high-resolution CT scanning [47].

\section{Obstructive lung disease}

Several endoscopic approaches are studied in patients with severe obstructive lung diseases, including endobronchial valves, coils, application of steam and targeted lung denervation. Most novel techniques are still in various stages of study evaluation.

The REACH study, a RCT, compared endoscopic valve therapy $(n=66)$ to optimal medical management $(n=35)$ in 101 subjects with advanced heterogeneous upper or lower lobe predominant emphysema. Absent interlobar collateral ventilation $(\mathrm{CV})$ was confirmed by $\mathrm{CT}$ fissure analysis. Patients treated by valves experienced a target lobe volume reduction of $66 \%$ at 6 and 12 months of follow-up. Compared to the control group, the treatment group achieved a significant and clinically meaningful improvement in FEV1 during follow up visits over 1 year. The most common complications observed in the treatment group were COPD exacerbations (21\%) and pneumothoraces (11\%). Therefore, the REACH trial is the first RCT that demonstrated 12 months of sustained, clinically meaningful benefit in patients with severe emphysema and absent CV following valve placement [48]. The combination of quantitative CT (QCT) and Chartis measurements might further improve bronchoscopic lung volume reduction response rates. In another study in 318 severe emphysema patients, QCT-determined thoracoscopic lung volume reduction (TLVR) was analysed and the minimal important difference (MID) in TLVR was calculated using an anchor-based method using FEV1, residual volume and SGRQ. The combined MID in TLVR was established at $-563 \mathrm{~mL}(-22.4 \%)$ at 6 months follow-up [49].

Bronchial thermoplasty (BT) is an endoscopic treatment for severe asthma that aims to impact airway remodelling and, as such, differs from immune-modulating therapies for asthma. In the PAS-2 registry, reduction in severe asthma exacerbation (45\%), hospitalisations (55\%) and emergency department visits (40\%) was observed in 190 BT-treated patients after 3 years follow-up. These outcomes mirror the AIR-2 trial results in "real-world practice" in a more severe asthma population [50]. Next to clinical outcome, the impact of BT on airway remodelling could be detected in both biopsies (mucin 5A and protein arginine $N$-methyltransferase 1 expression and airway smooth muscle reduction) and QCT (reduction in wall thickness and air trapping) [51-54]. 


\section{Group 1.5: Diffuse Parenchymal Lung Disease}

Most abstracts and sessions on diffuse parenchymal lung disease were focused on IPF, from single-centre or registry reports on long-term analysis on safety and efficacy of the two available antifibrotic drugs [55-58]. Great relevance was also given to the presentation of the results of clinical phase II trials and data on quality of life of patients affected by IPF.

Targeted medicine in ILD demands better phenotyping and endotyping of patients, and therefore a better knowledge of different potential pathogenic mechanisms. Multiple genetic biomarkers, such as specific transforming growth factor- $\beta$, single-nucleotide polymorphisms and telomeres, have been associated with poor clinical outcomes in IPF [59-62], while certain microRNAs may be used to improve diagnostic accuracy and evaluation of treatment response. Non-primarily fibrotic pathogenic pathways, including the inflammasome, may also represent promising therapeutic targets [63, 64].

Furthermore, among risk factors for IPF development, exposure to air pollution has been evaluated in 2093 incident IPF cases in Northern Italy [65]. Increasing $\mathrm{NO}_{2}$, but not $\mathrm{O}_{3}$, concentrations were associated with increased incidence of IPF.

Early diagnosis, especially in IPF, is a challenging issue since a delay can impact long-term disease outcomes. Primary care physicians should receive an adequate training to better recognise crackles/ clubbing or radiological findings, as stated by RIVERA ORTEGA et al. [66]. In relation to patients' signs and symptoms, VAN MANEN et al. [67] reported a prevalence of clubbing up to $41 \%$ in patients with fibrotic ILDs, but this sign showed no correlation with disease severity.

Functional imaging techniques, like hyperpolarised ${ }^{3} \mathrm{He}$ gas MRI or ${ }^{18} \mathrm{~F}$-fluorodeoxyglucose PET/CT, show that regional morphological changes can be correlated with respiratory impairment, and have a potential role as predictors of disease outcome and treatment response [68,69]. A study by RoBbiE et al. [70] also showed that annual anterior junction distance change at CT scan was a better predictor of mortality than annual FVC change.

In recent years, a new diagnostic tool, transbronchial cryobiopsy (TCB), has been increasingly used in clinical practice. A study by PoLETTI [71] showed that the diagnostic accuracy of TCB increased when two samples, rather than one, were taken from different segments. In another real-life report, WÄLSCHER et al. [72] reported pneumothorax in $11 \%$ and mild to moderate bleeding in $28 \%$ of cases, as main complications, but no cases of acute exacerbations. Through MDT discussion, final diagnoses were reached in $86 \%$ of cases. Similar real-life results, with a diagnostic yield of $87.5 \%$, were also reported by MARTINS Morais et al. [73].

Multidisciplinary discussion, the gold standard approach for ILD diagnosis, has also been matter of debate. WALSH et al. [74] compared the diagnostic performance of 404 physicians from all over the world to a panel of 34 IPF experts. Regular multidisciplinary discussion meeting attendance improved the prognostic accuracy of experienced non-university practitioners to levels achieved by IPF experts.

Acute exacerbation is one of the most feared complications in patients with ILDs due to its poor prognosis. Data on extracorporeal membrane oxygenation, in comparison to mechanical ventilation and noninvasive oxygen therapy, showed a favourable effect on survival in a multivariate analysis [75].

Results from two innovative phase II trials in IPF were presented during the ERS Congress. The PRAISE RCT on pamrevlumab has been presented by RICHELDI et al. [76]; this anti-connective tissue growth factor monoclonal antibody has been shown to stabilise FVC in 48 weeks of treatment and reduce mortality in treated patients versus placebo during 12 months observation. Data from a phase $\mathrm{Ib}$ trial on a selective JNK inhibitor (c-Jun N-terminal kinase, CC-930001) showed it to be associated with an overall lack of FVC decline and acceptable safety over 12 weeks of treatment in patients with IPF [77]. The INJOURNEY trial on nintedanib and pirfenidone in combination has shown that nintedanib plasma trough concentrations are not influenced by add-on pirfenidone [78]. Furthermore, combination treatment was well tolerated overall and the safety profile was similar to that expected with either treatment alone [79].

The evidence for wide use of rituximab in the management of connective tissue disease-associated ILD is growing. In 31 cases of rheumatoid arthritis-associated ILD, rituximab was able to stabilise lung functional decline and joint manifestations in a consistent proportion of patients [80]; in inflammatory myopathies, clinical and radiological stability was achieved in five out of seven patients. Neither study reported any severe adverse event [81].

Patients' quality of life was one of the major topics in ILD at this conference. Depression and anxiety have been reported to be highly prevalent in IPF (up to $39 \%$ according to Tzouvelekis et al. [82]) and to negatively impact on disease severity, quality of life and burden of symptoms [83]. Despite their clinical 
relevance, these conditions are highly misdiagnosed and might be accompanied by disregard of patients' expectations about treatment and lower compliance, as reported by Moor et al. [84].

\section{Group 1.6: General Practice and Primary Care}

The rich and wide-ranging primary care programme at the ERS Congress 2017 began with the primary care day on Saturday, September 9. The value of multidisciplinary working for community management of chronic diseases was promoted by Jaime Correia De Sousa and its importance further emphasised by Antonio Caviglia who shared how in some settings, respiratory care remained largely specialist led, with primary care practitioners used predominantly to implement the management plan received. Ideas to improve connectivity between patients, community and healthcare teams were shared by Sinthia Bosnic-Anticevich, and the potential for telehealth and digitised health systems to impact healthcare delivery highlighted by Klaus Phanareth and Aziz Sheikh, respectively.

\section{Lung disease in low-resource countries}

Further perspectives on healthcare delivery came from authors reporting from low-resource countries. Asthma and COPD were found to have considerable impact on healthcare use and spending in four low-resource settings [85], with wide variation in beliefs and understanding of the causes and consequences of lung disease between countries [86]. Encouragingly, vAN GEMERT et al. [87] were able to teach communities about lung health and the damaging effects of biomass and tobacco smoke by broadening existing educational programmes.

\section{Self-management}

Across all health settings, optimising delivery of supported self-management for airway disease was an important research theme. Patients prefer tailored self-management, thoughtful of their language and culture [88], and allowing their personal needs to be discussed [89]. The support provided by a healthcare professional is important for stimulating and continuing self-management [90], though the level of support required is likely to vary between patients. Internet [91] and telephone-based [92] self-management interventions were not successful in improving health outcomes, but may offer advantages for some patient groups.

Thомаs et al. [93] demonstrated that a self-guided breathing retraining intervention delivered by DVD and booklet were effective in improving the quality of life of adults with incompletely controlled asthma, whilst healthcare costs were reduced compared to usual care.

\section{Predicting future risk}

Identifying at-risk individuals was the subject of several studies. A systematic review completed by BEULO et al. [94] identified past exacerbation and persistent symptoms as strong predictors of future asthma attack in children aged 5-12 years. HоNKOоp et al. [95] developed a risk prediction score to determine the chance of future uncontrolled asthma in adults.

KASTELYN et al. [96] considered the value of the COPD Assessment Test (CAT) in predicting future exacerbations. In patients with severe obstructive disease (FEV $1<50 \%$ predicted), a CAT score $>20$ was the most useful predictor of an exacerbation in the next year. A further predictive model derived by HeNNY et al. [97] found that IgG2 and thrombocytes were potentially useful predictors of future COPD exacerbation.

Overall, the quality and depth of primary care respiratory research from around the world was very impressive, stimulating much debate and making us look forward to the ERS Congress 2018 in Paris, France.

\section{Concluding remarks}

The authors of this article hope that this comprehensive summary of the impressive amount of lung research and advances in pulmonary care presented through the Clinical Assembly of the ERS creates curiosity to follow up on topics of interest to each individual reader.

It was our goal to stimulate discussion and exchange of scientific novelties and clinical developments. We also hope to have encouraged the readership to attend the ERS International Congress 2018 in Paris.

\section{References}

1 Koblizek V, Zindr V, Kocianova J, et al. Discordance between a patient completed COPD Assessment test (CAT) and a CAT completed by patient with physician assistance. Eur Respir J 2017; 50: Suppl. 61, PA3626.

2 Nishimura K, Nakamura S, Kusunose M, et al. Comparison between electronic and paper versions of the Evaluating Respiratory Symptoms in COPD (E-RS) and the COPD Assessment Test (CAT). Eur Respir J 2017; 50: Suppl. 61, PA3630. 
3 Lindqvist A, Bajc M, Wang J, et al. High CAT score predicts lung parenchymal damage in COPD. Eur Respir J 2017; 50: Suppl. 61, PA4965.

4 Demeyer H, Waschki B, Polkey M, et al. The survival effect of physical activity in patients with COPD: every step counts. Eur Respir J 2017; 50: Suppl. 61, OA512.

5 Watz H, Troosters T, Beeh K, et al. ACTIVATE: effect of aclidinium/formoterol on physical activity in patients with COPD. Eur Respir J 2017; 50: Suppl. 61, PA687.

6 Cazzola M, Calzetta L, Ora J, et al. LABA/LAMA combination, exercise and lung hyperinflation in COPD: a meta-analysis. Eur Respir J 2017; 50: Suppl. 61, PA683.

7 Crook S, Büsching G, Keusch S, et al. The longitudinal association of daily physical activity and symptoms of exacerbations in COPD patients. Eur Respir J 2017; 50: Suppl. 61, PA3467.

8 Boral I, Orme M, Harvey-Dunstan T, et al. An exploration of physical activity and sedentary behaviour during hospitalisation for acute exacerbation of chronic respiratory diseases. Eur Respir J 2017; 50: Suppl. 61, PA3458.

9 Chiaradia D, Rodó-Pin A, Sancho-Muñoz A, et al. Is iron deficiency modulating physical activity in COPD? Eur Respir J 2017; 50: Suppl. 61, PA3457.

10 Tamaki A, Kawaura G, Fujisawa C, et al. Relationship between physical activity, muscle thickness, and echo intensity in patients with chronic obstructive pulmonary disease: a cross-sectional study. Eur Respir J 2017; 50: Suppl. 61, PA3451.

11 Xavier R, Lopes A, Pereira AC, et al. Identification of phenotypes in COPD patients: influence of physical activity in daily life, body composition and skeletal muscle strength. Eur Respir J 2017; 50: Suppl. 61, OA518.

12 Kerkhof M, Rastogi S, Alacqua M, et al. Association between blood eosinophil count and risk of exacerbations in patients with COPD. Eur Respir J 2017; 50: Suppl. 61, PA3979.

13 Jusufovic E, Kosnik M, Becarevic M, et al. Peripheral blood eosinophils as marker of sputum eosinophilia and outcome of COPD exacerbation. Eur Respir J 2017; 50: Suppl. 61, PA3606.

14 Sciurba F, Chanez P, Martinot JB, et al. Mepolizumab reduces exacerbations in eosinophilic COPD. Eur Respir J 2017; 50: Suppl. 61, OA3194.

15 Dimitrova D, Youroukova V, Velikova T, et al. Serum levels of IL-6 in adult patients with moderate to severe asthma. Eur Respir J 2017; 50: Suppl. 61, PA1166.

16 Awopeju O, Salawu L, Salami O, et al. The relationship of serum interleukin-13 to asthma control in a sample of Nigerian asthmatics. Eur Respir J 2017; 50: Suppl. 61, PA1168.

17 Pabreja K, Gibson P, Baines K, et al. IL-27 and asthma endotypes - is there a connection? Eur Respir J 2017; 50 Suppl. 61, PA1159.

18 Kerkhof M, Tran T, van den Berge M, et al. Association between blood eosinophil count and exacerbation risk in patients with asthma receiving medium- or high-dosage inhaled corticosteroids. Eur Respir J 2017; 50: Suppl. 61 , PA3994.

19 Ulrik C, Baaarnes C, Andersen Z, et al. Determinants of incident asthma-COPD overlap compared to asthma and COPD alone: a prospective study of 55,110 middle-aged adults. Eur Respir J 2017; 50: Suppl. 61, OA318.

20 Mindus S, Malinovschi A, Ekerljung L, et al. Asthma and COPD overlap syndrome (ACOS) is related to a high burden of sleep disturbance and respiratory symptoms: results from the RHINE and Swedish GA2LEN surveys. Eur Respir J 2017; 50: Suppl. 61, OA317.

21 Hancox R, Pavord I, Sears M. Blood eosinophils and lung function decline in young adults. Eur Respir J 2017; 50 Suppl. 61, OA320.

22 Castro N, Campos J, Cuvillobernal A, et al. Prevalence of traffic accidents in patients diagnosed with asthma and/ or rhinitis. Eur Respir J 2017; 50: Suppl. 61, OA1485.

23 Kumar R, Guleria R, Khilnani GC, et al. The effects of pulmonary rehabilitation in patients with non-cystic fibrosis bronchiectasis- A randomized controlled trial. Eur Respir J 2017; 50: Suppl. 61, OA307.

24 Cole A, Nolan CM, Patel S, et al. Response to pulmonary rehabilitation (PR) in bronchiectasis and COPD: a propensity matched analysis. Eur Respir J 2017; 50: Suppl. 61, OA311.

25 Kaltsakas G, Anastasopoulos N, Chynkiamis N, et al. Effect of high intensity interval exercise rehabilitation in cystic fibrosis. Eur Respir J 2017; 50: Suppl. 61, OA310.

26 Arizono S, Taniguchi H, Kondoh Y, et al. Effects of mean pulmonary arterial pressure and Suppl.emental oxygen on exercise capacity in IPF patients with exercise-induced hypoxemia. Eur Respir J 2017; 50: Suppl. 61, OA313.

27 Kaliaraju DP, William M, Nolan CM, et al. Unsupervised home-based versus supervised outpatient pulmonary rehabilitation (PR) in COPD: a propensity-matched, non-inferiority analysis. Eur Respir J 2017; 50: Suppl. 61 , OA308.

28 Coertjens P, Coertjens M, de Oliveira HG, et al. Relationship between stair climbing test and locomotor parameters after pulmonary rehabilitation. Eur Respir J 2017; 50: Suppl. 61, OA309.

29 Andrianopoulos V, Vogiatzis I, Gloeckl R, et al. Cerebral cortex blood flow response to exercise in COPD patients with and without cognitive impairment. Eur Respir J 2017; 50: Suppl. 61, OA312.

30 Mineshita $\mathrm{M}$, Inoue $\mathrm{T}$, Miyazawa $\mathrm{T}$, et al. The ratio of cardiac/lung area in expiratory plain chest radiographs correlates with the level of airflow limitation in patients with severe COPD. Eur Respir J 2017; 50: Suppl. 61 , PA3749.

31 Robbie H, Wells A, Jacob J, et al. Novel CT markers of volume loss in idiopathic pulmonary fibrosis (IPF) predict mortality. Eur Respir J 2017; 50: Suppl. 61, OA4643.

32 Bell A, Richardson M, Singapuri A, et al. Parametric response map registered CT feature and small airway physiology analysis in asthma. Eur Respir J 2017; 50: Suppl. 61, OA4647.

33 Diaz AA, Strand M, Coxson $\mathrm{H}$, et al. The variable relationship between changes in lung density and FEV 1 in smokers. Eur Respir J 2017; 50: Suppl. 61, PA797.

34 Tschirren J, McEleney S, Sieren J, et al. GOLD-associated shape variations in central airway tree assessed via QCT. Eur Respir J 2017; 50: Suppl. 61, PA795.

35 Eddy R, Sheikh K, Capaldi D, et al. Ventilation heterogeneity reversibility: asthma, COPD or ACOS? Eur Respir J 2017; 50: Suppl. 61, OA4646.

36 Hughes P, Smith L, Horn F, et al. Ventilation heterogeneity assessed in patients with mild cystic fibrosis and asthma using hyperpolarised gas MRI histogram analysis. Eur Respir J 2017; 50: Suppl. 61, OA4645. 
Chan HF, Parra-Robles J, Collier G, et al. Comparison of in-vivo lung morphometry models from multiple b-value diffusion-weighted MRI in healthy controls, IPF and COPD patients. Eur Respir J 2017; 50: Suppl. 61, OA4644.

38 Weatherley N, Chan HF, Stewart N, et al. Hyperpolarised gas MRI demonstrates sub-clinical progression in IPF over 6 months. Eur Respir J 2017; 50: Suppl. 61, OA4642.

39 Singh A, Sharma S, Tripathi M, et al. 68 Gallium DOTA-NOC PET/CT as a predictor of disease activity in sarcoidosis. Eur Respir J 2017; 50: Suppl. 61, OA4649.

40 Vilmann P, Clementsen PF, Colella S, et al. Combined endobronchial and oesophageal endosonography for the diagnosis and staging of lung cancer. Eur Respir J 2015; 46: 40-60.

41 Crombag LM, Dooms C, Annema JT, et al. Complete and systematic mediastinal nodal staging for lung cancer (SCORE study). Eur Respir J 2017; 50: Suppl. 61, OA1468.

42 Crombag LM, Annema JT, Dieleman E, et al. Complete endosonographic nodal staging of lung cancer in patients eligible for stereotactic ablative radiotherapy (STAGE study NCT02997449). Eur Respir J 2017; 50: Suppl. 61, OA1470.

43 Wijmans L, de Bruin M, Meijer S, et al. Needle based confocal laser endomicroscopy for lung cancer staging. Eur Respir J 2017; 50: Suppl. 61, OA1469.

44 Bhatnagar R. Malignant pleural effusion management: is combining pleurodesis techniques the way forward? Results of the IPC-PLUS trial. Eur Respir J 2017; 50: Suppl. 61, 4805.

45 Psallidas I, Kanellakis N, Thezenas M, et al. Prognostic and therapeutic markers of malignant pleural effusion the PROMISE study. Eur Respir J 2017; 50: Suppl. 61, OA292.

46 Caldas Marçôa AR, Linhas R, Apolinario D, et al. Diagnostic yield of transbronchial lung cryobiopsy in interstitial lung diseases. Eur Respir J 2017; 50: Suppl. 61, PA3032.

47 Wijmans L, de Bruin D, Jonkers R, et al. Visualizing the alveolar compartment in ILD patients by optical coherence tomography. Eur Respir J 2017; 50: Suppl. 61, OA1467.

48 Wang G, Shiyue Li S, Wang C, et al. The REACH study, a randomized controlled trial assessing the safety and effectiveness of the Spiration Valve System endobronchial therapy for severe emphysema: 12 month follow-up results. Eur Respir J 2017; 50: Suppl. 61, OA1465.

49 Schumann M, Gompelmann D, Kontogianni K, et al. Comparison of quantitative CT (QCT) with Chartis measurement to asess collateral ventilation as predictor of success in endoscopic lung volume reduction with valves. Eur Respir J 2017; 50: Suppl. 61, OA1466.

50 Chupp G, Laviolette M, Cohn L, et al. Long-term outcomes of bronchial thermoplasty in subjects with severe asthma: a comparison of 3-year follow-up results from two prospective multicentre studies. Eur Respir J 2017; 50: 1700017.

51 Chakir J, Haj Salem I, Gras D, et al. MUC5AC expression decrease correlates with the decline in rates of severe asthma exacerbations post bronchial thermoplasty. Eur Respir J 2017; 50: Suppl. 61, OA279.

52 Fang L, Roth M, Sun Q, et al. Bronchial thermoplasty restores constitutive high PRMT1 expression in asthmatic airways. Eur Respir J 2017; 50: Suppl. 61, OA4672.

53 D'Hooghe JNS, ten Hacken NHT, Roelofs JJTH, et al. Airway smooth muscle mass reduction after bronchial thermoplasty; the TASMA randomized controlled trial. Eur Respir J 2017; 50: Suppl. 61, PA3027.

54 Schumann M, Konietzke P, Wielpütz M, et al. Reduction of bronchial wall thickness and hyperinflation on quantitative CT after bronchial thermoplasty for severe asthma. Eur Respir J 2017; 50: Suppl. 61, PA3028.

55 Jo H, Glaspole I, Grainge C, et al. Disease progression at 12 months does not predict future outcomes in IPF patients: Analysis from the Australian IPF Registry. Eur Respir J 2017; 50: Suppl. 61, PA1947.

56 Lewandowska KB, Kus J, Zolnowska B, et al. Idiopathic pulmonary fibrosis (IPF) patients in Poland - preliminary cohort analysis of EMPIRE registry. Eur Respir I 2017; 50: Suppl. 61, PA3252.

57 Cottin V, Koschel D, Guenther A, et al. Long-term safety of pirfenidone in a real-world setting: final results from the prospective, observational PASSPORT registry. Eur Respir J 2017; 50: Suppl. 61, PA5418.

58 Prasse A, Kreuter M, Klotsche J, et al. Gender associated differences in patients with IPF based on the analysis of the INSIGHTS-IPF registry data. Eur Respir J 2017; 50: Suppl. 61, OA4637.

59 Ulitina A, Novikova L, Ilkovich J, et al. Association between AGT, TGFB1, ESR1, and VDR gene variants with idiopathic pulmonary fibrosis (IPF) and pulmonary sarcoidosis (PS) clinical features. Eur Respir J 2017; 50: Suppl. 61, OA4288.

60 Downey GP, Aschner Y. Protein tyrosine phosphatase-alpha (PTP $\alpha$ ) promotes profibrotic responses in lung fibroblasts. Eur Respir J 2017; 50: Suppl. 61, PA1890.

61 Garcia Moyano M, Planas L, Bullich M, et al. Post-transplant morbidity and mortality in patients with pulmonary fibrosis and telomeric shortening. Eur Respir J 2017; 50: Suppl. 61, PA1874.

62 Guiot J, Struman I, Chavez M, et al. Altered epigenetic features in circulating nucleosomes in idiopathic pulmonary fibrosis. Eur Respir J 2017; 50: Suppl. 61, PA5286.

63 Terlizzi M, Imitazione P, Colarusso C, et al. Role of the inflammasome in idiopathic pulmonary fibrosis. Eur Respir J 2017; 50: Suppl. 61, PA4568.

64 Nita I, Gazdhar A, Vonarburg C, et al. $\alpha_{1}$-Antitrypsin reduces endoplasmic reticulum stress, inflammatory cytokines and improves wound repair in alveolar epithelial cells of fibrotic lung in vitro. Eur Respir J 2017; 50 Suppl. 61, PA2638

65 Conti S, Harari S, Caminati A, et al. An observational study on the effect of air pollution on the incidence of idiopathic pulmonary fibrosis in Italy. Eur Respir J 2017; 50: Suppl. 61, PA2906.

66 Rivera Ortega P, Luburich P, Ferrer F, et al. Benefits from a program for "early interstitial lung diseases" in primary care centers. Eur Respir J 2017; 50: Suppl. 61, OA4029.

67 van Manen MJ, Vermeer LC, Moor CK, et al. Clubbing in patients with fibrotic interstitial lung diseases. Eur Respir J 2017; 50: Suppl. 61, PA554.

68 Weatherley N, Chan H-F, Stewart N, et al. Hyperpolarised gas MRI demonstrates sub-clinical progression in IPF over 6 months. Eur Respir J 2017; 50: Suppl. 61, OA4642.

69 Lanclus M, Porter S, Mignot B, et al. Responder phenotyping using functional respiratory imaging (FRI) in IPF patients treated with anti-CGTG monoclonal antibody FG3019. Eur Respir J 2017; 50: Suppl. 61, PA5516.

70 Robbie H, Wells A, Jacob J, et al. Novel CT markers of volume loss in idiopathic pulmonary fibrosis (IPF) predict mortality. Eur Respir J 2017; 50: Suppl. 61, OA3108. 
Poletti V. Transbronchial cryobiopsy in diffuse parenchymal lung disease. Eur Respir J 2017; 50: Suppl. 61, 1392. Wälscher J, Eberhardt R, Heußel CP, et al. Real world experience with transbronchial cryobiopsies for diagnosing interstitial lung disease (ILD). Eur Respir J 2017; 50: Suppl. 61, OA3532.

Martins Morais AM, Melo N, Mota P, et al. Transbronchial criobiopsy (TCB) in two lung lobes - diagnostic accuracy. Eur Respir J 2017; 50: Suppl. 61, PA4327.

Walsh S, Hansell D, Maher T, et al. Accuracy of a clinical diagnosis of idiopathic pulmonary fibrosis. A study of 404 pulmonologists from 57 countries. Eur Respir J 2017; 50: Suppl. 61, PA3275.

Ohshimo S, Kida Y, Kyo M, et al. Extracorporeal membrane oxygenation for the treatment of acute exacerbation of interstitial lung diseases. Eur Respir J 2017; 50: Suppl. 61, OA3356.

Richeldi L, Raghu G, Fernandez Perez E, et al. PRAISE, a randomized, placebo-controlled, double-blind Phase 2 clinical trial of pamrevlumab (FG-3019) in IPF patients. Eur Respir J 2017; 50: Suppl. 61, OA1430.

Greenberg S, G Horan G, B Bennett B, et al. Evaluation of the JNK inhibitor, CC-90001, in a phase 1b pulmonary fibrosis trial. Eur Respir J 2017; 50: Suppl. 61, OA5562.

Wuyts W, Grutters JC, Kreuter M, et al. Pharmacokinetics (PK) of nintedanib with add-on pirfenidone in patients with idiopathic pulmonary fibrosis (IPF): results from INJOURNEY. Eur Respir J 2017; 50: Suppl. 61, PA5430.

Flaherty K, Fell CD, Huggins JT, et al. Safety of combined pirfenidone (PFD) and nintedanib (NIN) in patients with idiopathic pulmonary fibrosis (IPF). Eur Respir J 2017; 50: Suppl. 61, PA5417.

Nieto Barbero MA, Vadillo Font C, Calderon Alcala M, et al. Rituximab improves interstitial lung disease in rheumatoid arthritis patients. Eur Respir J 2017; 50: Suppl. 61, PA2675.

Riddell P, O'Mahony A, Murphy G, et al. Rituximab in the management of idiopathic inflammatory myopathies complicated by interstitial lung disease. Eur Respir J 2017; 50: Suppl. 61, PA4662.

Tzouvelekis A, Kourtidou S, Bouros E, et al. Impact of depression on patients with idiopathic pulmonary fibrosis. Eur Respir J 2017; 50: Suppl. 61, PA411.

83 Nolan CM, Patel S, Barker RE, et al. Anxiety and depression in idiopathic pulmonary fibrosis (IPF): prevalence and clinical correlates. Eur Respir J 2017; 50: Suppl. 61, PA1324.

4 Moor C, Kimman ML, van Manen MJ, et al. Discrepancy between patient expectations and experiences with anti-fibrotic drugs in idiopathic pulmonary fibrosis. Eur Respir J 2017; 50: Suppl. 61, PA2577.

5 van Boven JFM, Brakema EA, Walusimbi S, et al. Health economic burden of asthma/COPD in Uganda, Vietnam, Kyrgyzstan and Greece: FRESH AIR results. Eur Respir J 2017; 50: Suppl. 61, OA2911.

Brakema E, van der Kleij R, Poot C, et al.. Beliefs and behaviours towards chronic lung disease - a mixed-method FRESH AIR study. Eur Respir J 2017; 50: Suppl. 61, PA3891.

van Gemert F, Kirenga B, Jones $\mathrm{R}$, et al. The development and implementation of a lung health awareness programme in a rural district of Uganda. Eur Respir J 2017; 50: Suppl. 61, PA3895.

Abramson MJ, Wan ACS, Thien F, et al. Ethnic differences in asthma management in Australia. Eur Respir J 2017; 50: Suppl. 61, PA1607.

9 Zakrisson A-B, Arne M, Hasselgren M, et al. A description of requests for self-management support among patients with COPD in primary health care. Eur Respir J 2017; 50: Suppl. 61, PA1605.

Van Noort E, Kasteleyn M, Veen H, et al. Self-management by eHealth in asthma and COPD patients: with or without the professional. Eur Respir J 2017; 50: Suppl. 61, PA1606.

Tamboom-Kamp E, Kasteleyn M, Verdijk N, et al. Effect on health status of integrated self-management platforms in COPD disease-management. Eur Respir J 2017; 50: Suppl. 61, OA2912.

Jolly K, Sidhu M, Hewitt C, et al. Telephone health coaching in primary care patients with MRC I/II COPD: randomised controlled trial. Eur Respir J 2017; 50: Suppl. 61, OA2914.

Thomas M, Bruton A, Yardley L, et al. Breathing exercises for asthma - results of the BREATHE study. Eur Respir J 2017; 50: Suppl. 61, OA2913.

4 Buelo A, Mclean S, Flores-Kim J, et al. A systematic review to identify and weight indicators of risk of asthma exacerbations in children aged 5-12. Eur Respir J 2017; 50: Suppl. 61, OA2916.

5 Honkoop P, Boer S, Loijmans R, et al. Personalised prediction of future risk using early treatment response. Eur Respir J 2017; 50: Suppl. 61, PA1602.

Kasteleyn M, Esquinas C, Barrecheguren M, et al. Identifying cut off scores for the chronic obstructive pulmonary disease assessment test (CAT) to predict exacerbations in COPD. Eur Respir J 2017; 50: Suppl. 61, OA2918.

Henny S, Dieterle T, Brack T, et al. A prediction model for exacerbations in patients with COPD generated in a Swiss multicenter COPD cohort study (TOPDOCS). Eur Respir J 2017; 50: Suppl. 61, PA1599. 